\title{
OCCUPATIONAL STRESS AS A CORRELATE OF ORGANISATIONAL CITIZENSHIP BEHAVIOUR AND PSYCHOLOGICAL CAPITAL AMONG GRADUATE EMPLOYEES IN NIGERIA
}

\author{
JOHN K. ADERIBIGBE ${ }^{1}$ \\ THEMBA Q. MJOLI ${ }^{2}$ \\ ${ }^{l}$ University of Fort Hare, South Africa/Nigeria Police Academy, Department of Industrial Psychology, Wudil, \\ Nigeria \\ ${ }^{2}$ University of Fort Hare, South Africa, Department of Industrial Psychology
}

(C) 2018 John K. Aderibigbe, Themba Q. Mjoli

This is an open access article distributed under the Creative Commons Attribution-NonCommercial-NoDerivs license (http://creativecommons.org/licenses/by-nc-nd/3.0/)

DOI: 10.1515/eras-2018-0005

\begin{abstract}
It is a documented fact that occupational stress is widespread worldwide. Moreover, there are clear signs of many variables, related to occupational stress. The study therefore, was conducted to demonstrate whether the presence of occupational stress in the world of work correlates in any form (positive or negative) with a better level of organisational performance and employee psychological wellbeing.

The study adopted the positivist explanatory cross-sectional (survey) research design to systematically sample opinions of 1,532 male and female graduate employees across the various sectors of the Nigerian economy, using a structured and validated questionnaire, and the Statistical Package for the Social Sciences (SPSS).

The results showed that there was a weak positive relationship between occupational stress and organisational citizenship behaviour $(\mathrm{r}=0.070, \mathrm{p}<0.01)$; there was a significant positive relationship between occupational stress and psychological capital $(\mathrm{r}=0.128, \mathrm{p}<0.01)$; and there was a significant positive relationship between psychological capital and organisational citizenship behaviour $(r=0.588, p<0.01)$.

The study recommended that human resource managers should develop psychological capital in employees in order to increase their levels of organisational performance and reduce the negative impact of occupational stress.
\end{abstract}

Keywords: Human resource, Management, Organisation, Performance, Occupational Stress

\section{INTRODUCTION}

Scholars have linked challenges that are related to employee performance in current employment to high levels of occupational stress (Baxter, 2010; Laschinger, 2011). In the same vein, studies have shown that occupational stress is significantly related to both task related work behaviour and non-task related work behaviour of employees (Adebiyi, 2013; Arogundade \& Lawal, 2016). The World Health Organization has also reported occupational stress as a global epidemic (WHO, 2010). Obviously, the consequence of an increasingly strenuous work environment is evident in Nigerian work settings, as cases of job dissatisfaction, a high rate of absenteeism, employee intention to quit, labour turnover, and poor job performance (contrast to organisational citizenship behaviour) remain evident among graduate employees in Nigeria (Adebayo \& Ogunsina, 2011; Adebiyi, 2013; Adetayo, Ajani \& Olabisi, 2014; Arogundade \& Lawal, 2016).

So far, broad studies throughout the years have centred more on identifying the stressors (Paillé, 2011; Brynien \& Igoe, 2016). Literature further reveals that most studies conducted on occupational stress have concentrated on determinants, as opposed to results, 
such as employee performance, turnover intention, turnover behaviour and employee productivity (American Psychological Association, 2013; Goh, Pfeffer \& Zenios, 2015). Hence, few scientific investigations have been conducted to devise psychological intervention strategies to ameliorate the situation and ensure organisational citizenship behaviour (Ahmad, Hussain, Saleem, Qureshi \& Mufti, 2015).

Furthermore, though there is an increasing consideration of the phenomenon of organisational citizenship behaviour by researchers, a thorough review of the literature shows a lack of agreement about the scope of the concept (Farzianpour, Foroushani, Kamjoo \& Hosseini, 2011). However, the current study sought to empirically examine occupational stress as a correlate of organisational citizenship behaviour and psychological capital in order to fill the existing vacuum identified in the literature.

The purpose of the study is twofold. Firstly, to examine the nature of relationships among occupational stress, organisational citizenship behaviour and emotional intelligence. Secondly, to recommend effective human resource management strategies through the findings of the study.

\section{CONCEPTUAL LITERATURE, EMPIRICAL LITERATURE REVIEW AND STATEMENT OF HYPOTHESES}

\subsection{CONCEPTUAL LITERATURE}

\subsubsection{OCCUPATIONAL STRESS}

Occupational stress is a negative career-related concept that generates concerns among career holders, and it has the ability to influence individual and organisational outcomes (Beheshtifar \& Nazarian, 2013). In other words, occupational stress is a negative phenomenon, the occurrence of which often stimulates an unpleasant response to the work environment making it appear threatening to the employees. Moreover, prolonged occupational stress could manifest itself physically, emotionally and psychologically in the lives of the affected employees.

The commonly reported physical symptom of occupational stress is a headache, which makes the affected employees unconsciously tense in their necks, foreheads and shoulder muscles (Chandra \& Parvez, 2016). The other known symptoms of occupation stress are digestive problems, ulcers, hypertension, anxiety and inordinate sweating, coronary illness, strokes and even male pattern baldness (Chandra \& Parvez, 2016).

Emotionally, an affected employee frequently displays nervousness, outrage, depression, fractiousness, frustration to ordinary issues, dementia and an absence of focus for any assignment, because the mind of the individual is negatively impacted. The psychological manifestations of occupational stress, on the other hand, include withdrawal from society, phobias, compulsive behaviours, eating disorders and night fears (Chandra \& Parvez, 2016).

\subsubsection{ORGANISATIONAL CITIZENSHIP BEHAVIOUR}

Organisational citizenship behaviour is an essential phenomenon in the formal work setting because of its potency to facilitate interpersonal relationships among employees, and also to increase organisational performance (Pradhan, Jena \& Bhattacharya, 2016). Organisational citizenship behaviour is an alternative form of performance behaviour, which 
is differentiated from the traditional performance that relies heavily on official assignments and tasks (Karolidis, 2016). For instance, having subordinates who are highly engaged in organisational citizenship may improve managers' efficiency by allowing them to devote a greater amount of time to long-range planning matters. Hence, managers, employees and the organisations at large benefit from the positive behaviours (Lelei, Chepkwony \& Ambrose, 2016). These behaviours are explained by concepts such as pro-social behaviours, extra-role behaviours, contextual performance, spontaneous behaviours or organisational citizenship behaviour.

\subsubsection{PSYCHOLOGICAL CAPITAL}

The term 'psychological capital' (PsyCap) is a composite construct that is defined according to Luthans et al. (2007) as "a person's positive mental state of improvement, which is described by: (1) having confidence (self-efficacy) to take on and put in the needed effort so as to prosper at challenging responsibilities; (2) making a positive attribution (optimism) about succeeding now and in the future; (3) determining toward goals and, when necessary, diverting ways to objectives (hope) with a specific end goal to succeed; and (4) when affected by issues and afflictions, managing, enduring and even going past (resilience) to reach success". According to Aliyev and Tunc (2015), psychological capital is a collection of abilities such as self-efficacy, optimism and endurance that are open to improvement, and it implies more than the collection of the aforementioned skills.

Specifically, capital signifies the quality of inviduals' assets (human capital) as well as in connection with other constructs such as social capital, cultural capital and intellectual capital (Amunkete, 2015). The term 'psychological capital' also denotes individual motivational inclinations that accumulate through desirable psychological concepts such as optimism, resilience, hope and efficacy (Luthans et al., 2007). Besides, psychological capital is recognized in the situation of a venture in psychic resources that results in getting realistic incentives from the current moment while also brightening the prospect of future benefits. It is about the condition of the segment of an individual's inner life (Amunkete, 2015).

\subsection{EMPIRICAL LITERATURE REVIEW}

\subsubsection{RELATIONSHIP BETWEEN OCCUPATIONAL STRESS AND ORGANISATIONAL CITIZENSHIP BEHAVIOUR}

In a recent descriptive-correlational study of the relationship between organisational citizenship behaviour and occupational stress that was conducted among 122 midwives at Mashhad, Iran, by Nourani, Kohansal, Esmaily and Hooshmand (2016), it was found that there is a significant negative association between organisational citizenship behaviour and occupational stress. Likewise, Arogundade and Lawal (2016) investigated the influence of perceived occupational stress on the organisational citizenship behaviour among 300 male and female bankers in Lagos, Nigeria, using a simple random sampling technique. Though results of the study revealed that there is no significant difference in the levels of organisational citizenship behaviour that were exhibited by bankers with higher stress levels and those with lower stress levels, there is an inverse relationship between occupational stress and organisational citizenship behaviour.

Moreover, Soo and Ali (2016) studied the linkage between occupational stress and organisational citizenship behaviour among a sample of 472 bankers in Malaysia. The 
findings of Soo and Ali's (2016) study revealed that there is a significant negative impact of occupational stress on organisational citizenship behaviour. In the same vein, Gregory, Yitzhak and Steffen (2016) scientifically examined the proposed need to distinguish between self-initiated and organisationally imposed overload in studies of work stress, using three samples, which consisted of 116 male and female full-time employed students in three countries, some nursing staff of six private hospitals in Switzerland, and 161 middle managersupervisor dyads in Switzerland. The study reveals in its findings that self-initiated imposed overload is significantly, positively related to organisational citizenship behaviour, but organisationally imposed overload is not a significant predictor of organisational citizenship behaviour.

Furthermore, Ikonne and Madukoma (2016) conducted a survey on the relationship among organisational citizenship behaviour, job stress and satisfaction among 109 librarians in some selected universities around the south-west region of Nigeria. The results of the study show that there is a significant negative relationship between organisational citizenship behaviour and job stress.

In addition, Uzonwanne (2014) conducted a survey research on depression, anxiety and stress as correlates of organisational citizenship behaviour, using the accidental sampling technique to sample 151 female and 149 male employees of oil and gas companies in Ogun State, Nigeria. The outcomes of the research show that there is a significant positive relationship between occupational stress and organisational citizenship behaviour. The findings of the study also indicate that, though there is a statistical positive relationship between the two variables, the observed positive relationship is weak considering the $r$ value of 0.118 , which is close to 0 .

\subsubsection{RELATIONSHIP BETWEEN OCCUPATIONAL STRESS AND PSYCHOLOGICAL CAPITAL}

Haq (2014) investigated the relationships among psychological capital, job stress, job performance turnover intention and ostracism in a sample of 229 paired respondents of full time employee working in different organisations in Pakistan, using a structured questionnaire as the survey instrument. The results of the study showed that there is a moderate positive relationship between psychological capital and job stress.

Similarly, Ding et al. (2015) studied the relationships among psychological capital, emotional exhaustion, depersonalization and reduced personal accomplishment in a sample of 1,496 nurses from public hospital in Daqing City, China, using a structured questionnaire. The results of the investigation revealed that self-efficacy, hope, resilience and optimism of nurses were all negatively related with emotional exhaustion.

Likewise, in a cross-sectional survey, Li et al. (2015) explored the relationships of psychological capital, emotional exhaustion, reward, overcommitment, depersonalization and personal accomplishment among a sample of 1239 employees in Liaoning, China, using a structured questionnaire to elicit data from the participants. The results of the survey indicated that there is a significant negative relationship between psychological capital and emotional exhaustion.

\subsubsection{RELATIONSHIP BETWEEN ORGANISATIONAL CITIZENSHIP BEHAVIOUR AND PSYCHOLOGICAL CAPITAL}

Ali-Shah and Ali-Shah (2016) adopted a longitudinal research design approach to investigate the relationship between psychological capital and organisational citizenship 
behaviour among 411 male and female employees of telecommunication firms in Pakistan, using a structured questionnaire as an instrument of data collection. The results of the investigation revealed that psychological capital and the in-role performance type of organisational citizenship behaviour are significantly positively interrelated.

Similarly, Suifan (2016) examined the impact of psychological capital on organisational citizenship behaviour among 277 male and female staff of Jordanian banks, using a survey design and a questionnaire to elicit information from the participants. The results of the statistical analysis that was performed on the data based on the stated hypothesis showed that there is a significant positive relationship between psychological capital and organisational citizenship behaviour.

Moreover, Paul, Bamel and Garg (2016) in their exploratory study of the relationship between resilience and organisational citizenship behaviour within the context of Indian organisations, sampled 345 employees who were working in the manufacturing industries of Uttarakhand and Himachal Pradesh in India. Data were collected in the study with a selfadministered questionnaire through the systematic sampling method. The findings of the study proved that there is a positive relationship between resilience and organisational citizenship behaviour.

In addition, Shaheen, Bukhari and Adil (2016) examined the relationship between psychological capital and organisational citizenship behaviour among 325 male and female bank employees in the private and public sectors in Rawalpindi and Islamabad cities of Pakistan, using a convenience sampling technique and a questionnaire to sample the opinions of the participants. The results of the study indicated that psychological capital is positively related to organisational citizenship behaviour.

\subsection{STATEMENT OF HYPOTHESES}

Based on the past studies reviewed and on logical grounds, the present study states the following hypotheses:

\section{Hypothesis 1}

H0: Occupational stress is not significantly positively correlated with organisational citizenship behaviour.

H1: Occupational stress is significantly positively correlated with organisational citizenship behaviour.

\section{Hypothesis 2} capital.

H0: Occupational stress is not significantly positively correlated with psychological capital

H1: Occupational stress is significantly positively correlated with psychological

\section{Hypothesis 3}

H0: Organisational citizenship behaviour is not significantly positively correlated with psychological capital.

H1: Organisational citizenship behaviour is significantly positively correlated with psychological. 


\section{RESEARCH METHODOLOGY}

\subsection{RESEARCH DESIGN, SAMPLE AND PROCEDURE}

The study adopted a positivist explanatory cross-sectional (survey) research design. The explanatory cross-sectional (survey) research was considered appropriate for the study because the research used the positivist approach by means of quantitative data generation, and hypotheses testing (Bhattacherjee, 2012).

The probability (The North Carolina Center for Public Health Preparedness' (2013) two-stage sampling scheme, and The Research Advisor (2006) Calculated Sample Size Table), and non-probability sampling (purposive and convenience) techniques were employed in this investigation.

The sample comprised of $916(60 \%)$ male and $616(40 \%)$ female graduate employees from 19 sectors of the Nigerian economy. Among the participants, 202 (13.2\%) were graduate employees from the educational sector, 38 (2.5\%) from the research institutes, 51 (3.3\%) from the transportation sector, 291 (19\%) from the finance and insurance sector, $83(5.4 \%)$ from the fast moving and consumable goods (FMCG) Industry, 21 (1.4\%) from the commercial sector, $70(4.6 \%)$ from the healthcare sector, $8(0.5 \%)$ from the aviation sector, $77(5.0 \%)$ from the agricultural sector, 57 (3.7\%) from the information. All participants were Nigerians English speakers.

The participants' ages ranged from 20 years to 65 years old. Relatively, $974(63.6 \%)$ of the participants were senior staff while the remaining $558(36.4 \%)$ were junior staff. Conclusively, among the participants, $730(47.7 \%)$ were employed by the government while the remaining $802(52.3 \%)$ were working under the employment of private organisations.

Data were collected by means of paper-pencil inventories (structured validated questionnaires), which were distributed to employees in the large lecture auditoriums during their weekend (Saturdays) part-time professional postgraduate programmes, in the three renowned public and private universities (University of Ibadan, Obafemi Awolowo University and the Pan-Atlantic University), situated in Oyo, Osun and Lagos states of Nigeria.

\subsection{ETHICAL CONSIDERATION}

The participants' voluntary participation in the study was sought through a letter of consent, signed by each of the participants. The participants were informed about the importance of the study as the findings from the study may positively influence the government policy helping in improving their conditions of employment and service respectively. Moreover, assurance was given to the participants in respect of confidentiality of all information supplied.

Furthermore, the participants were instructed not to indicate any means of identification such as name, identity number or organisational affiliation. With utmost sense of sincerity, information concerning the study and its outcomes was accurately submitted to the appropriate institutions. Thus, it was ensured that no instance of misleading actions was demonstrated in the course of the study. The researchers also ensured that the study was conducted in a conducive environment such that would not expose the participants to any physical or psychological hazard. The Research Ethics Committee of University of Fort Hare furthermore granted approval for ethical clearance of the study (Certificate reference number: MJO071SADE01). 


\subsection{MEASURING INSTRUMENTS}

Three established scales of measurement were employed to assess psychological capital, occupational stress and organisational citizenship behaviour.

\subsubsection{OCCUPATIONAL STRESS}

A 9-item scale of job stress that was developed and validated by Jamal and Baba (1992) was utilised to measure occupational stress. The measure was designed with a 5-point Likert-type response format ranging from 1/ (Strongly disagree) to 5/ (Strongly agree). The authors reported a Cronbach Alpha ecoefficiency score of 0.83 for the scale. However, the outcome of the pilot factor analysis of this study reduced the scale-item to 7, and yielded Cronbach Alpha ecoefficiency scores of 0.81 , while the main study's factor analysis yielded a Cronbach Alpha ecoefficiency score of 0.80 for the measure of occupational stress.

\subsubsection{ORGANISATIONAL CITIZENSHIP BEHAVIOUR}

A 15-item modified version of Podsakoff, Mackenzie, Moorman, and Fetter's (1990) organisational citizenship behaviour questionnaire by Argentero, Cortese and Ferretti (2008) was utilised to measure organisational citizenship behaviour. The construct consisted of altruism, conscientiousness and civic virtue sub-scales, with a 5-point Likert-type response format ranging from $1 /$ (Strongly disagree) to $5 /$ (Strongly agree). Argentero, Cortese and Ferretti (2008) reported the following Cronbach Alpha coefficients for the scale: altruism $=0.81$, conscientiousness $=0.73$, civic virtue $=0.73$ and 0.84 for the whole scale of organisational citizenship behaviour. However, the outcome of the pilot factor analysis of this study reduced the scale-item to 13, and yielded Cronbach Alpha ecoefficiency of 0.88 (altruism), 0.81 (conscientiousness), 0.86 (civic virtue) and 0.93 for the whole scale of organisational citizenship behaviour, while the main study's factor analysis yielded a Cronbach Alpha ecoefficiency score of 0.82 for the whole scale of organisational citizenship behaviour.

\subsubsection{PSYCHOLOGICAL CAPITAL}

A 24-item scale of psychological capital that was developed and validated by Luthans et al. (2007) was utilised to measure psychological capital. The construct consisted of selfefficacy, hope-state, optimism-state and resilience-state sub-scales, with a 5-point Likert-type response format ranging from 1/ (Strongly disagree) to 5/ (Strongly agree). The authors reported a Cronbach Alpha ecoefficiency score of 0.91 for the scale. However, the outcome of the pilot factor analysis of this study reduced the scale-item to 21, and yielded Cronbach Alpha ecoefficiency scores of 0.88 (self-efficacy), 0.91 (hope), 0.85 (resilience), 0.67 (optimism) and 0.94 for the whole scale of psychological capital, while the main study's factor analysis yielded a Cronbach Alpha ecoefficiency score of 0.85 for the whole scale of psychological capital.

\subsection{STATISTICAL ANALYSIS OF DATA}

The data generated from 1,532 screened questionnaires were analysed based on the hypotheses stated, using version 20 of the Statistical Package for the Social Sciences (SPSS). Hypotheses 1, 2 and 3 were analysed, using Pearson Correlation Analysis, while the 
percentage, mean, standard deviation and the frequency of the biographical and occupational data were also determined by the descriptive statistics.

\section{RESEARCH RESULTS}

The stated hypotheses were analysed using Pearson Correlation Analysis. The results of the analysis are therefore presented in the table 1 below:

\begin{tabular}{|c|c|c|c|}
\hline Variable & OCB & PsyCap & OS \\
\hline Organisational citizenship beh. (OCB) & 1 & $.473 * *$ & $.070^{* *}$ \\
sig. (2-tailed) & & .000 & .006 \\
$\mathrm{n}$ & 1532 & 1532 & 1532 \\
\hline Psychological capital (PsyCap) & $.588^{* *}$ & & $.128^{* *}$ \\
sig. (2-tailed) & .000 & & .001 \\
$\mathrm{n}$ & 1532 & 1532 & 1532 \\
\hline Occupational stress (OS) & $.070^{* *}$ & $.086^{* *}$ & 1 \\
sig. (2-tailed) & .006 & .001 & 1532 \\
$\mathrm{n}$ & 1532 & 1532 & \\
\hline
\end{tabular}

From the table presented above, the results show that there is a weak positive relationship between occupational stress and organisational citizenship behaviour, $r=0.070$, $\mathrm{p}<0.01$. This implies that even though there is a positive relationship observed between occupational stress and organisational citizenship behaviour, the level of the observed relationship between the two aforementioned variables is very feeble, considering the given significance value, $0.006=0.01$ (approximated to 2 decimal points), which is exactly the maximum limit of acceptable value of significance at the 0.01 level (2-tailed). The results further explain that though there is an indication of a positive relationship between occupational stress and organisational citizenship behaviour, but the observed level of relationship between the two variables is not reliable enough. Thus perhaps, it requires the introduction of one or more positive variables, to serve as moderators or mediators in order to yield a more significant and reliable relationship. Therefore, based on the results and interpretations above, hypothesis $1 \mathrm{H} 0$ was rejected, while hypothesis $1 \mathrm{H} 1$ was confirmed.

In the same vein, from the table presented above, the results show that there is a significant positive relationship between occupational stress and psychological capital, $\mathrm{r}=$ $0.128, \mathrm{p}<0.01$. The result implies that psychological capital is significantly positively related to occupational stress, the level of the observed relationship between the two aforementioned variables is moderate, considering the given significance value, 0.001 , which is significance at the 0.01 level (2-tailed). Based on the result and interpretation above, hypothesis $2 \mathrm{H} 0$ was rejected, while hypothesis $2 \mathrm{H} 1$ was confirmed.

Moreover, from the table presented above, the results show that there is a significant positive relationship between organisational citizenship behaviour and psychological capital, $r$ $=0.588, \mathrm{p}<0.01$. The result implies that organisational citizenship behaviour is significantly positively related to psychological capital, the level of the observed relationship between the two aforementioned variables is strong, considering the given significance value, 0.000 , which is significance at the 0.01 level (2-tailed). Based on the result and interpretation above, hypothesis $3 \mathrm{H} 0$ was rejected, while hypothesis $3 \mathrm{H} 1$ was confirmed. 


\section{DISCUSSION}

The results established the hypothesized relationships among occupational stress, organisational citizenship behaviour and psychological capital. A weak positive relationship was found existing between occupational stress and organisational citizenship behaviour. This explains that though there is an indication of a positive relationship between occupational stress and organisational citizenship behaviour, but the observed level of positive relationship between the two variables is not reliable enough. Thus perhaps, it requires the introduction of one or more positive variables, to serve as moderators or mediators in order to yield a more significant and reliable relationship. These findings corroborate the reports of Uzonwanne (2014), which states that there is a weak positive relationship between occupational stress and organisational citizenship behaviour. Similarly, Soo and Ali (2016) report further that selfinitiated imposed work-overload is significantly, positively related to organisational citizenship behaviour, but organisationally imposed overload is not a significant predictor of organisational citizenship behaviour.

Concerning the results of the hypothesis 2 , the findings show that there is a significant positive relationship between occupational stress and psychological capital. The results explain that there is an indication of a reasonable level of positive relationship between occupational stress and psychological capital. This explains that although, stress naturally seems to be negative, but a moderate amount of it could yield positive psychological states of development. For instance, a reasonable amount of stress expressed by a job incumbent could make an employee to be more efficacious, hopeful, resilient and optimistic, most especially when success is often coming after the experience of stress. Thus perhaps, justifies the importance of challenging corporate tasks and assignments to employees and organisations.

These findings are supported by the findings of Haq (2014) whose study shows that there is a moderate positive relationship between psychological capital and job stress. In contrast to this, Ding et al. (2015) report shows that self-efficacy, hope, resilience and optimism of nurses were all negatively related with emotional exhaustion. Likewise, Li et al. (2015) indicate that there is a significant negative relationship between psychological capital and emotional exhaustion.

Lastly, the results of hypothesis 3 show that there is a significant positive relationship between organisational citizenship behaviour and psychological capital. The result implies that organisational citizenship behaviour is significantly positively related to psychological. These results are in line with the expectation that employees with higher levels of positive orientations will contribute significantly higher, beyond the border or scope of their job duties and responsibilities, to assist co-employees and customers or client in order to enable the organisation to achieve her goals and objectives. The present findings corroborate the findings of Ali-Shah and Ali-Shah (2016), which revealed that psychological capital and the in-role performance type of organisational citizenship behaviour are significantly positively interrelated. Similarly, Suifan (2016) reports that there is a significant positive relationship between psychological capital and organisational citizenship behaviour. Moreover, Paul, Bamel and Garg's (2016) study demonstrated that there is a positive relationship between resilience and organisational citizenship behaviour.

\section{CONCLUSION}

This study concludes that there is a weak positive relationship between occupational stress and organisational citizenship behaviour. It further concludes that occupational stress is significantly positively related to psychological capital. It was also concluded that organisational citizenship behaviour and psychological capital are correlated. The study 
finally concludes that occupational stress, organisational citizenship behaviour and psychological capital are significantly interrelated.

\section{LIMITATIONS OF THE STUDY AND SUGGESTIONS FOR FUTURE RESEARCH}

The first noticeable shortcoming of this research relates to bias in the approach of data collection. The research only adopted the quantitative method, which limited the opinions of research respondents to the response options provided to statements in the questionnaire. This study therefore, suggests that future studies should consider adopting more than one method of data collection.

The second acknowledged limitation of this study is the fact that the study was designed only to explore the relationship among variables under consideration. Because of this reason, the study could not specifically categorise variables into classes of dependence and independence, therefore further limits the generalisation of the findings. Future research should test beyond the relationships among the variables.

\section{RECOMMENDATION}

In view of the above discussion of the findings, the researchers make the following practical recommendations:

- that the tertiary institutions' management, most especially of the universities, should incorporate in their academic curricula some practical simulated work exercise that will pre-expose the graduating students to the challenges at the world of work. This will build their psyche, and make them mentally and emotional ready to overcome any stressful situation that may come their way, even in the cause of discharging of career duties or responsibilities through the positivist approach. This can be achieved by a deliberate inclusion of moderately difficult practical group assignments in the syllabus that will task each student in a group, to proactively think 'outside the box' and proffer visible solutions in the form of suggestions to the problems at hand. By so doing, students will develop a reasonable level of positive orientations along with the acquired theoretical knowledge of their disciplines while the universities can as well boast of producing capable graduate who will fit perfectly into the realities of the world of work and promptly deliver.

Human resource managers, seminar facilitators, workshop trainers and supervisors should focus on training the individual employees or graduates to discover their covert behavioural endowments such as psychological capital, and make them refined through a systematic training process that converts the covert behavioural gifts into overt psychological assets in the form of demonstrable managerial competencies, which can enhance their performance on the job, and enable them to be pro-social among colleagues in the work settings. 


\section{REFERENCES}

Adebayo, S.O. \& Ogunsina, S.O. (2011). Influence of supervisory behaviour and job stress on job satisfaction and turnover intention of police personnel in Ekiti State. Journal of Management and Strategy, 2(3): 1320.

Adebiyi, D.R (2013). Occupational stress among academic staff of Ekiti State University, Ado-Ekiti. European Scientific Journal, 9(4): 202-208.

Adetayo, J.O., Ajani J.O. \& Olabisi, O. (2014). An overview of the effects of job stress on employees' performance in Nigeria Tertiary Hospitals. Ekonomika, 60(4): 139-153.

Ahmad, A., Hussain, A., Saleem, M.Q., Qureshi, M.A.M. \& Mufti, N.A. (2015). Workplace stress: A critical insight of causes, effects and interventions. Technical Journal, University of Engineering and Technology, Taxila, Pakistan, 20 (2): 45-55

Ali-Shah, T. \& Ali-Shah, S.Z. (2016). Combined effects of psychological capital and psychological contract on employees' job level outcomes. European Journal of Business and Management, 8(26): 5-19.

Aliyev, R. \& Tunc, E. (2015). Self-efficacy in counceling: The role of organizational psychological capital, job satisfaction and burnout. Procedia-Social Beh. Sci., 190: 97-105.

American Psychological Association (2013). Stress in America: Missing the health care connection.

Amunkete, S.L.N. (2015). Psychological capital in Namibian state-owned enterprises: measurement, antecedents and outcomes. Ph.D Thesis, North-West University, South Africa.

Argentero, P., Cortese, C.G. \& Ferretti, M.S. (2008). Organisational citizenship behaviour: Podsakoff et al.'s scale. TPM, 15(2): 61-75.

Arogundade, O.T. \& Lawal, O. (2016). The influence of perceived occupational stress on the organizational citizenship behaviour of bankers in Ikeja, Lagos State. European Scientific Journal, 12(17): 449-458.

Baxter, P.E. (2010). Providing orientation programs to new graduate nurses: Points to consider. Journal for Nurses in Staff Development, 26: E12-E17.

Beheshtifar, M. \& Nazarian, R. (2013). Role of occupational stress in organizations. Interdisciplinary Journal of Contemporary Research in Business, 4 (9): 648-657.

Bhattacherjee, A. (2012). Social science research: Principle, methods and practices. Textbook collection. Book 3.

Brynien, K. \& Igoe, A. (2016). Occupational stress factsheet. PEF Health and Safety Department: (800) 342$4306 \times 254$ or (518) 785-1900 x 254.

Chandra, N. \& Parvez, R. (2016). A review article: Impact of environmental and occupational stress on health. Paripex - Indian Journal of Research, 5(5): 456-457.

Ding, Y., Yang, Y., Yang, X., Zhang, T., Qiu, X., He, X., Wang, W., Wang, L. \& Sui, H. (2015). The mediating role of coping style in the relationship between psychological capital and burnout among Chinese Nurses. PLoS ONE, 10(4): e0122128. DOI: 10.1371/journal.pone.0122128.

Farzianpour, F., Foroushani, A.R., Kamjoo, H. \& Hosseini, S.S. (2011). Organisational citizenship behaviour (OCB) among the managers of teaching hospitals. American Journal of Economics and Business Administration 3(3): 534-542.

Goh, J., Pfe!er, J., \& Zenios, S. A. (2015). Workplace stressors \& health outcomes: Health policy for the workplace. Behavioural Science \& Policy, 1(1): 43-52.

Gregory, A.L., Yitzhak, F. \& Steffen, R. (2016). Evidence for the need to distinguish between self-initiated and organizationally imposed overload in studies of work stress. Work \& Stress, 30(4): 337-355, DOI: $10.1080 / 02678373.2016 .1253045$.

Haq, I.U. (2014). Workplace ostracism and job outcomes: moderating effects of psychological capital. International Conference on Management, Knowledge and Learning, 25-27 June 2014, Portoroz, Slovenia.

Ikonne, C.N. \& Madukoma, E. (2016). An investigation of the relationship between job satisfaction, job stress and organizational citizenship behavior: A research on librarians in Nigerian University Libraries. International Journal of Science and Research, 5(8): 480-484.

Jamal, M. \& Baba, V.V. (1992). Shiftwork and department type related to job stress, work attitudes and behavioural intentions: A study of nurses. Journal of Organisational Behaviour, 13: 449-464.

Karolidis, D. (2016). Organisational citizenship behaviour in the Greek public sector. Interdependent Programme of Postgraduate Studies in Business Administration, University of Macedonia.

Laschinger, H.K.S. (2011). Job and career satisfaction and turnover intentions of newly graduated nurses. Journal of Nursing Management. Advance online publication.

Lelei, J.C., Chepkwony, P.K. \& Ambrose, K. (2016). Effect of organisational citizenship behaviour on employee performance in banking sector, Nairobi County, Kenya. International Journal of Business, Humanities and Technology, 5(4): 55-61. 
Li, X., Kan, D., Liu, L., Shi, M., Wang, Y., Yang, X., Wang, J., Wang, L. \& Wu, H. (2015). The mediating role of psychological capital on the association between occupational stress and job burnout among bank employees in China. International Journal of Environmental Research and Public Health, 12: 29843001; doi:10.3390/ijerph120302984.

Luthans, F., Avolio, B.J., Avey, J.B., \& Norman, S.M. (2007). Psychological capital: Measurement and relationship with performance and satisfaction. Personnel Psychology, 60: 541-572.

North Carolina Center for Public Health Preparedness (2013). Two-stage cluster sampling: general guidance for use in public health assessments. Cited in Aramide, O.K. (2014). Relationship between the use of family planning related information and attitudes of rural childbearing women toward family planning. A Ph.D Thesis, Postgraduate School, Babcock University, Nigeria, 73-75.

Nourani, S.S., Kohansal, D.Z., Esmaily, H. \& Hooshmand, E. (2016). The relationship between organisational citizenship behaviour, job satisfaction and occupational stress among Midwives Working in Healthcare Centers of Mashhad, Iran. Journal of Midwifery and Reproductive Health, 4(2): 622-630.

Paillé, P. (2011). Stressful work, citizenship behaviour and intention to leave the organization in a high turnover environment: Examining the mediating role of job satisfaction. Journal of Management Research, 3 (1): $1-14$.

Paul, H., Bamel, U.K. \& Garg, P. (2016). Employee resilience and organisational citizenship behaviour: Mediating effects of organizational commitment. The Journal for Decision Makers, 41(4): 308-324.

Podsakoff, P. M., Mackenzie, S.B, Moorman, R.H., \& Fetter, R. (1990). Transformational leader behaviours and their effects on followers' trust in leader, satisfaction and organisational citizenship behaviour. The Leadership Quarterly, 1(2): 107-142.

Pradhan, R.K. \& Jena, L.K. \& Bhattacharya, P. (2016). Impact of psychological capital on organizational citizenship behaviour: Moderating role of emotional intelligence. Cogent Business \& Management, 3(1): 1-16.

Shaheen, S., Bukhari, I., \& Adil, A. (2016). Moderating role of psychological capital between perceived organizational support and organizational citizenship behaviour and its dimensions. International Journal of Research Studies in Psychology, 5(2): 41-50.

Soo, H.S. \& Ali, H. (2016). The linkage between stress and organizational citizenship behaviour. International Business Management 10(14): 2713-2718.

Suifan, T.S. (2016). The impact of organizational climate and psychological capital on organizational citizenship behaviour. International Journal of Business and Management, 11(1): 224-230.

The Research Advisors (2006). http://research-advisors.com.

Uzonwanne, F.C. (2014). Depression, anxiety and stress as correlates of organizational citizenship behaviour among oil workers in Nigeria. European Journal of Globalization and Development Research, 10(1): 619-637.

World Health Organization (2010). Healthy workplaces: A model for action for employers, workers, policymakers and practitioners. Geneva: WHO. 